\title{
Auditory evoked potentials during selective listening to dichotic speech messages
}

\author{
ROBERT F. HINK and STEVEN A. HILLYARD \\ Department of Neurosciences, University of California, San Diego, La Jolla, Califormia 92093
}

\begin{abstract}
The sensitivity of the scalp-recorded, auditory evoked potential to selective attention was examined while subjects monitored one of two dichotically presented speech passages for content. Evoked potentials were elicited to irrelevant probe stimuli (vowel sounds) embedded in both the right- and the leftear's message. The amplitude of the evoked potential was larger to probe stimuli embedded in the attended message than to probe stimuli in the unattended message. Recall performance was unaffected by the presence of the probes. The results are interpreted as supporting the hypothesis that this evoked potential sensitivity reflects an initial "input selection" stage of attention.
\end{abstract}

An auditory stimulus which onsets abruptly elicits a characteristic sequence of electrical responses recordable from the human scalp, reflecting the transmission and processing of the signal by subcortical and cortical brain centers (Picton, Hillyward, Krausz, \& Galambos, 1974). The most prominent components of this auditory evoked potential (EP) are the cortical " $\mathrm{N}_{1}$ " and " $\mathrm{P}_{2}$ " waves, which make their appearance at about 100 and $170 \mathrm{msec}$ poststimulus, respectively. Recently, the relative amplitudes of the $N_{1}$ waves evoked by concurrent multiple sound sources has been shown to rellect the selective distribution of attention among those channels (Hillyard, Hink. Schwent, \& Picton, 1973; Schwent \& Hillyard, 1975; Schwent, Hillyard, \& Galambos, in press a, b; Schwent, Snyder, \& Hillyard, Note 1). When attention was directed to a tone source having a particular pitch and/or spatial position (i.e., belonging to a particular channel), those tones elicited larger $N_{1}$ waves than when attention was directed to one of the competing channels. These authors proposed that $\mathrm{N}_{1}$ amplitude was an index of an initial stage of selective attention whereby stimuli are sele:ted (or rejected on the basis of having (or lacking) particular physical attributes such as pitch, location, or color. This mode of attention, which enables a rapid and efficient rejection of unwanted sensory data based on these physical cues, has been variously termed "stimulus set" (Broadbent \& Gregory, 1964), "filtering" (Broadbent, 1971). "attenuation" (Treisman, 1964), or "input selection" (Treisman, 1969).

Supported by USPHS Grant MH 25594.01 to Steven A. Hillyard and NASA Grant NGR 05-009-198 to Robert Galambos. Grateful thanks are given to Mrs. Pennie Hink, whose help in the analysis of the data and preparation of the manuscript was invaluable. Also, special thanks are extended to David $L$. Woods for his good ideas and technical assistance. Present address of Robert F. Hink: Department of Psychiatry. Veterans Administration Hospital. 3801 Miranda Avenue. Palo Alto, California 94304.
The stimuli used in most prior electrophysiological studies of selective attention have been rather unnatural-clicks, tones, noise bursts, and the like, which do not play a large role in the normal human listener's environment. The most important form of human auditory communication, listening to meaningful passages of speech, has been particularly neglected in EP research on attention (see Näätänen, 1975, for a thorough review). This is unfortunate, considering the profound attention effects that have been demonstrated when subjects attempt to listen selectively to one of two or more competing spoken messages (Broadbent, 1958; Cherry, 1953; Moray, 1970). Very little information can be extracted from speech stimuli in irrelevant channels, whether subjects are required to actively repeat (shadow) the relevant material or simply to monitor its contents (Moray \& O'Brien, 1967; Underwood \& Moray, 1971).

In the present study, auditory EPs were recorded to irrelevant "probe" stimuli embedded within dichotically presented passages of meaningful prose, in order to discover whether selective listening to speech is reflected in these brain responses in the same fashion as with artificial sounds. More specifically, we wished to test the generality of the proposition that $N_{1}$ amplitude indexes the "stimulus set" selection between auditory channels, irrespective of the complexity or relevance of the material being selected. To ensure that this listening task required subjects to attend selectively. a second study was performed comparing conditions of divided vs. focused attention. Finally, to our knowledge, this is the first study where subjects monitored meaningful, connected speech passages for comprehension and subsequent recall rather than shadowed them directly. Information concerning the relative degree of selectivity engendered by the monitoring prosedure is of interest in light of the hypothesis that response or output competition accounts for some of the selectivity in the shadowing task (Reynolds, 1964). 


\section{EXPERIMENT I}

\section{Method}

Subjects. Ten university students, five male and tive fermale, serral as paid, voluntecer subjects.

Stimuli. Dichotic specti nessiges, prerecorded on two channels of a fisur-channel audio lape recorder (Akai 280D-S.s), were played through stereo headphones. The left-ear material was taken from The Diary of Anne Frank and was spoken in a temale voice. The rightecar material was taken from two short storics by Ambrose Bierce and was spoken in a male voice. The verbal material was presented with a mean intensity of $40 \pm 6 \mathrm{~dB}$ SPL at an average rate of 150 words/min. These two concurrent stories were segmented into ruas of about 4 min in duration. The segments were ordered so that the story line from each source was maintained over alternate runs. Therefore. as the subject changed the ear to which he was listening on successive runs, he heard two complete literary selections.

The probe stimuli were synthesized phonemes (Bell speech synthesizers) sounding like the rowel sound "ah." Each had an intensify of $71 \mathrm{~dB} \mathrm{SPL}$ and a duration of $50 \mathrm{msec}$. The left-ear probes differed in freyuency structure from those in the right ear. The two types of probes were matched in the fundamental and tirst three formant freguencies to the voices of the male and temale speakers, respectively, as determined frum sound spectrograms (Sulograph 60 th $\mid A$ ). The proties were superimposed at random intervals upon the appropriate spetech channel using a Sony MX-12 acoustic mixer. The iwo types of probes (male and female) were delivered in random seyuential order at intervals collapsed across chanmels ranging between 1.1 and $1.7 \mathrm{sec}$ (rectangular distribution). The probe sequences wete recorded on the remaining two channels of the audio tape in parallel with the specech, so that wach subje:t experiched preciscly the same tenupural relation between probes and speech. Continuous binaural white noise (Grason-Stadler Model $\times 1-B$ ) at a kevel of $36 \mathrm{~dB}$ SPL was also mised with the speech and probes.

Procedure. The subject was seated comtortably in an acoustically shiekded chamber and was told to minimive movements of face. eyes. and longue while listening to the speech. An experiment consisted of 14 runs, each lasting about $4 \mathrm{~min}$. In the first two runs. the subject was instructed to read a book. He was presented with either probes alone or probes superimposed on reversed spech. These conditions were included to assess the purely acoustic effects of "speech-like" sounds on the E.Ps to prohes. The last two runs (Nos. 1.3 and 14) were replicates of the first two runs, but in reversed arder.

On the remaining 10 runs $(N o .3$ through No. 12), the subject was lold that his primary task was to listen carefully to the message in a designated ear and be prepared to take a quiz on its subject niatter afterwards. His secondary task was to "pick up" whatever he happened to hear on the contralateral message on which he wnuld also be quized. All prohes were to be disregarded. $\mathrm{He}$ alternatcly nonitored one ear and then the opposite on successive runs. Haif of the subjects began this sequence by attending to the left car, while the other half started with the right ear. On wo of these runs. the probes were withheld to find out if they impaired comprchension of the specth. These no-probe control runs occupied symmetric positions about the center of the sequence (i.e.. Nos. 3 and 12, or Nos. 4 and 11 , etc.). The five possible symmetric positions were counterbalanced across all subjects.

Tests. The tests used for evaluating comprehension and recall of ench 4-min passage consisted of 10 multiple-choice questions. The questions required recall of rather detailed information in order to minimize the effects of possible preexperiment exposure and to increave the independence of the different questions. Two tests were ginen lollowing cach run. one tor the material in each ear: the atlended-ear cyuis was given first on half of the runs and second on the wher half. in counterbalanced order.

EP recording and analysis. Auditury EPs were recorded from the vertex $\left(C_{2}\right)$ and from sites lateral to $C_{3}$ and $C_{4}$ by $10 \%$ of the

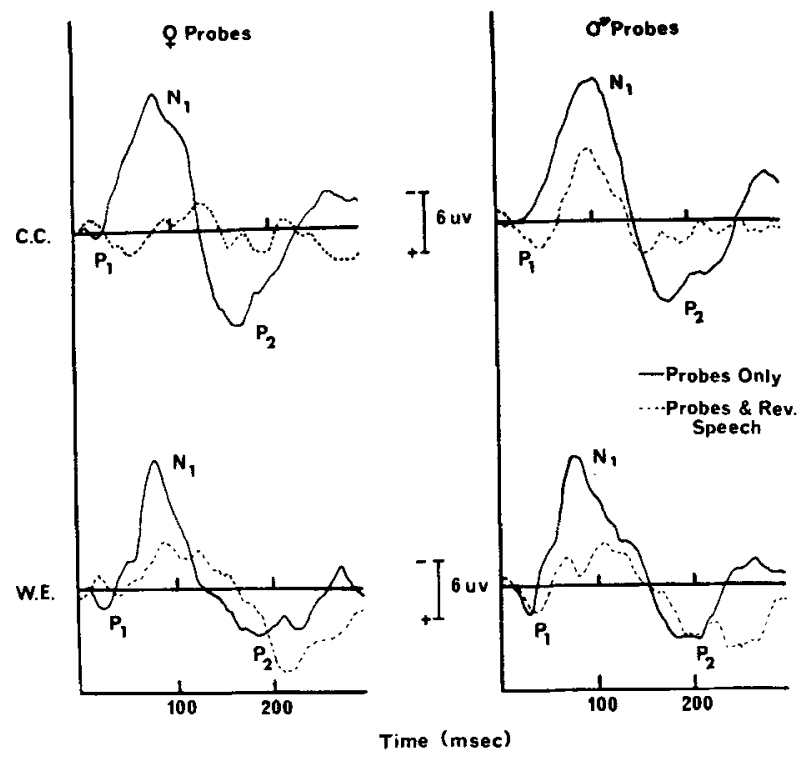

Figure 1. Effects of reversed speech on the probe-evoked potentials (at $C_{z}$ ). The subjects were told to read a book in both conditions. Each waveform was averaged over 96 responses. These data are from two representative subjects (C.C. and W.E.).

interaural distance, ali referred to the right car lobe. The electro-oculogram was recorded between the uppet and lower orbital ridges to the right cye. Brair, potentials were amplified using a Grass Model 6 polvgraph (ficyuancy response down $3 \mathrm{~dB}$ at 0.3 and $70 \mathrm{~Hz}$ ) and were stured on FM tape (TMC Model 700 ) $/ 1400$ ) fir off-line averaging with a Nicolet 1072 signal averager.

Measurements of EP components were made from X-Y plots (Houston Instruments HR-95) of these averages. Averages were taken over the middle 5, probe presentations for each ear during cach run. Triak with eve hlinks or excessive muscle contamination werc deleted from the itcrage. The EP components were identified on the hasis of four criteria: latency. polarity, amplitude. and distribution. For example. $P_{1}$ was taken to be the largest positive wave which occurred in all three scalp recordings between 25 and 80 nsec poststimulus. The $N_{1}$ and $P_{2}$ waves were similarly defined with littency ranges of $80-120 \mathrm{msec}$ and $140-250 \mathrm{msec}$. respectively. Pcak-to-peak amplitudes were calculated for these components, as were baseline-to-peak amplitules. with the baseline taken as the mein voltage over the first $20 \mathrm{msec}$ of the EP waveform. Experimental effects on EP components were assessed with repeated measures analyses of variance.

\section{Results}

Effects of masking on EPs. The masking properties of the backwards speech and noise upon the EP to probes are illustrated in Figure 1. As expected, the presence of reversed speech and white noise considerably reduced the amplitude of both $P_{1}-N_{1}$ (by an average of $58.4 \%, p<.001$ ) and $N_{1}-P_{2}$ (by $59.7 \%$, $\mathrm{p}<.001$ ) in the passive conditions (see Table 1). The latency of $P_{1}$ was significantly increased by the presence of noise and reversed speech (by an average of $9.5 \mathrm{msec}, p<.001$ ), while the peak latencies of $\mathbf{N}_{1}$ and $P_{2}$ were not changed by the masking sounds (Table 2).

Effects of attention on EPs. The effects of manipulating the direction of attention are displayed in Figure 2 for two representative subjects. Each 
Table 1

Mean EP Amplitudes (in Microvolts $\pm S E$ ) at $C_{z}$ to Male $(M)$ and Female (F) Probes Under the Four Experimental Conditions

\begin{tabular}{|c|c|c|c|c|}
\hline & \multicolumn{2}{|c|}{$P_{1}-N_{2}$} & \multicolumn{2}{|c|}{$N_{1}-P_{2}$} \\
\hline & $\begin{array}{l}\text { F Probe } \\
\text { (L Ear) }\end{array}$ & $\begin{array}{l}\text { M Probe } \\
\text { (R Ear) }\end{array}$ & $\begin{array}{l}\text { F Probe } \\
\text { (L Ear) }\end{array}$ & $\begin{array}{l}\text { M Probe } \\
\text { (R Ear) }\end{array}$ \\
\hline Passive (probes only) & $10.2 \pm 1.0$ & $9.5 \pm 1.1$ & $14.8 \pm 1.5$ & $12.8 \pm 1.8$ \\
\hline Passive (with noise and reversed speech) & $4.3 \pm .4$ & $3.9 \pm .8$ & $6.6 \pm .9$ & $4.6 \pm .7$ \\
\hline Attend $\mathrm{M}$ speaker & $3.1 \pm .4$ & $3.1 \pm .3$ & $4.6 \pm .7$ & $5.8 \pm .8$ \\
\hline Attend $\mathrm{F}$ speaker & $4.1 \pm .6$ & $2.6 \pm .2$ & $6.7 \pm .9$ & $3.9 \pm .4$ \\
\hline
\end{tabular}

Table 2

Mean Component Latencies (in Milliseconds \pm SE) to Male (M) and Female (F) Probes Under the Four Experimental Conditions

\begin{tabular}{|c|c|c|c|c|c|c|}
\hline & \multicolumn{2}{|c|}{$P_{1}$} & \multicolumn{2}{|c|}{$\mathbf{N}_{1}$} & \multicolumn{2}{|c|}{$P_{2}$} \\
\hline & $\begin{array}{l}\text { F Probe } \\
\text { (L Ear) }\end{array}$ & $\begin{array}{r}\text { M Probe } \\
\text { (R Ear) }\end{array}$ & $\begin{array}{c}\text { F Probe } \\
\text { (L Ear) }\end{array}$ & $\begin{array}{l}\text { M Probe } \\
\text { (R Ear) }\end{array}$ & $\begin{array}{l}\text { F Probe } \\
\text { (L Ear) }\end{array}$ & $\begin{array}{l}\text { M Probe } \\
\text { (R Ear) }\end{array}$ \\
\hline $\begin{array}{l}\text { Passive (probes only) } \\
\text { Passive (probes and reversed speech) } \\
\text { Attend M speaker } \\
\text { Attend F speaker }\end{array}$ & $\begin{array}{l}32 \pm 2 \\
41 \pm 4 \\
45 \pm 3 \\
42 \pm 3\end{array}$ & $\begin{array}{l}33 \pm 3 \\
43 \pm 4 \\
47 \pm 4 \\
48 \pm 7\end{array}$ & $\begin{array}{r}90 \pm 3 \\
89 \pm 5 \\
107 \pm 7 \\
102 \pm 8\end{array}$ & $\begin{array}{r}89 \pm 4 \\
91 \pm 5 \\
108 \pm 5 \\
105 \pm 9\end{array}$ & $\begin{array}{l}180 \pm 5 \\
190 \pm 11 \\
198 \pm 6 \\
199 \pm 8\end{array}$ & $\begin{array}{l}199 \pm 8 \\
191 \pm 9 \\
192 \pm 20 \\
184 \pm 13\end{array}$ \\
\hline
\end{tabular}

evoked potential (from $C_{Z}$ ) represents an average over 224 probe presentations across the four runs where attention was directed to a given ear. Both the $P_{1}-N_{1}$ and $N_{1}-P_{2}$ amplitudes were larger when the probes belonged to the same channel as the monitored speech in comparison to when attention was focused on the opposite channel. Over all subjects and runs, this attention effect amounted to a $25.3 \%$ enhancement in $P_{1}-N_{1}$ amplitude and a $47.1 \%$ enhancement in $N_{1}-P_{2}$ amplitude (Table 1); both differences were significant as rellected in the Stimulus by Attention Condition interactions (the Subject by Stimulus by Condition interaction was the error estimate, cf. Table 3). The percentage enhancement of $\mathrm{N}_{1}-\mathrm{P}_{2}$ was not significantly greater than that of $P_{1}-N_{1}$, however (Wilcoxon test, $p<.10$ ). Baseline-to-peak measures for both $\mathrm{N}_{1}$ and $\mathrm{P}_{2}$ waves showed significant attention effects as reflected in this two-way interaction ( $p<.025$ for each measure); a baseline- $P_{1}$ measure failed to show an attention effect.

To investigate whether the $\mathrm{N}_{1}-\mathrm{P}_{2}$ enhancement with attention received a contribution from a later, positive-going component (e.g., resolution of contingent negative variation), a third waveform measure was taken between the baseline (the voltage over the first $20 \mathrm{msec}$ of the trace) and the amplitude at a latency of $300 \mathrm{msec}$ (Wilkinson \& Ashby, 1974). The mean amplitude of this response to probes in the monitored ears was $0.0 \mu \mathrm{V}$, as compared to a mean of $-.02 \mu \mathrm{V}$ in response to probes in the nonmonitored ears. The Stimulus by Attention Condition interaction for this measure did not even approach significance $[F(1.9)=0.33]$.

The distribution of the evoked potential over the subject": head was found to oe laterally asymmetrical under both active and passive conditions (Taile 4). The $\mathrm{P}_{1}-\mathrm{N}_{1}$ measure was $11.7 \%$ larger over the left hemisphere than over the right $(p<.025)$ across all stimulus conditions and both probe stimuli. A similar lateral asymmetry of $16.4 \%$ was found for $\mathrm{N}_{1}-\mathrm{P}_{\mathrm{e}}$ ( $p<.01)$. Moreover, the right-ear probes (nale) elicited $N_{1}-P_{2} s$ having a greater left-scalp preponderance than did the lett-ear probe (female); over all conditions, the right-car probes elicited $\mathrm{N}_{1}-\mathrm{P}_{2}$ waves having a left-right asymmetry of $23.2 \%$. while the left-ear probes produced an asymmetry of only $9.3 \%(p<.025)$. Neither the direction of attention (left or right ear) nor the relative amount of altention directed to each ear affect this "standing" asymmetry signilicantly.

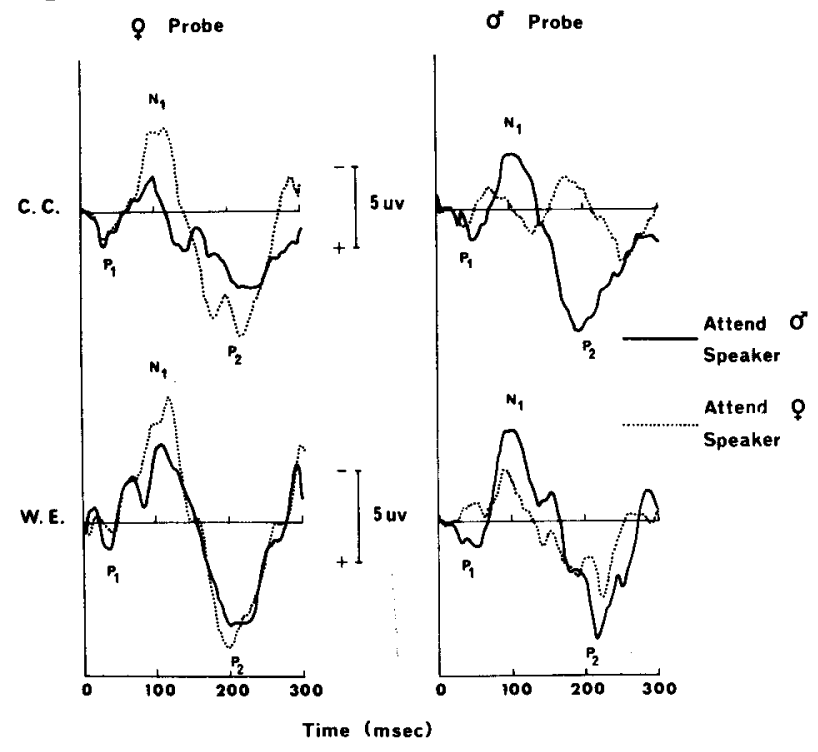

Figure 2. Effect of direction of attention on the auditory E.P. (at $C_{z}$ ) evoked by probe stimuli in the right ear (male) and the left ear (female). Each waveform averaged over 224 responses. These data are from two representative subjects (C.C. and W.E.). 
Table 3

Repeated Measures Analysis of Variance for EP Components (at $C_{z}$ ) in Active Attention Conditions

\begin{tabular}{lrrrr}
\hline Source & df & \multicolumn{1}{c}{ SS } & F \\
\hline & \multicolumn{5}{c}{ (A) $P_{1}-N_{1}$} \\
Subjects & 9 & 34.06 & & \\
Stimulus (M, F) & 1 & 5.11 & 3.20 & n.s. \\
Condition (attend M, F) & 1 & .42 & 1.21 & n.s. \\
Subjects by Stimulus & 9 & 14.38 & & \\
Subjects by Condition & 9 & 3.12 & & \\
Stimulus by Condition & 1 & 6.01 & 10.38 & p $<.02$ \\
Subjects by Stimulus by Condition & 9 & 5.21 & &
\end{tabular}

(B) $\mathrm{N}_{1}-\mathrm{P}_{2}$

Subjects

Stimulus (M, F)

Condition (attend $\mathrm{M}, \mathrm{F}$ )

Subjects by Stimulus

Subjects by Condition

Stimulus by Condition

9111.96

\begin{tabular}{lrll}
1 & 4.76 & 1.40 & n.s. \\
1 & .58 & 1.77 & n.s. \\
9 & 30.70 & & \\
9 & 2.93 & & \\
1 & 42.02 & 13.76 & p $<.01$ \\
9 & 27.49 & & \\
\hline
\end{tabular}

To investigate whether any of this left-hemisphere preponderance could be attributed to language processing. the degree of left/right asymmetry was compared between the passive, probes-only condition and the mean of the two active, probes-in-speech conditions. This comparison was made separately for each set of probes (i.e., for each ear). Only the test on $N_{1}-P_{2}$ to right-ear probes reach significance $(p<.01)$; the mean asymmetry in the active conditions was almost (wice that in the passive, probes-only condition (see lable 4). However, since the headphones were not reversed in this experiment, such language-related insymmetries in the EPs could be partially confounded with stimulus variables.

Finally, the mean latency of $N_{1}$ was found to be longer (by $17 \mathrm{msec}, p<.025$ ) over both active conditions than in the acoustically similar passive condition with reversed speech present. The $P_{2}$ wave showed no similar changes, however (Table 2). Component latencies did not exhibit any sensitivity to the dircetion of attention.

Test scores. As shown in Table 5, subjects demonstrated superior recall of the primary material
(P test) in comparison with recall of the secondary material (S test). However, the $S$-test scores averayed significantiy higher than the chance level of $20 \%$ $(p<.001)$ by sign test. ${ }^{1}$ The effects of test order and of the probes' presence were both nonsignificant.

\section{EXPERIMENT II}

The previous experiment demonstrated that the difierence in $P_{1}-N_{1}$ amplitude between attended and unattended channels was related to a comparable difference in the subjects' comprehension/recall of nuaterial in the two channels. The question remains, however, whether the markedly improved test scores for attended-ear material reflected true perceptual effect or whether a greater amount of effort or consideration was devoted to the attended-ear test, which was given primary emphasis in the instructions to the subject. One way to find out if the subjects really did attend selectively in this task would be to show that they were incapable of achieving as high scores when attention was divided between the two channels as when attention was focused on one channel. In this experiment, therefore, the subjects' comprehension of the same dichotically presented malerial used in Experiment $I$ is compared under conditions of focused attention (to one ear) and divided attention (to both ears at once). No EPs were recorded in this abbreviated study.

\section{Method}

Subjects. Truelve college students, six male and six female, served as paid subjects. None of them had participated in Experinent $I$.

Stimuli. The diclotic spoken messages were identical to those uscul in runs 3-8 ut Experiment 1 , except that the probe stinuli were withheld. The tests were also the sane ones used in the first experiuncill.

Procedure. The subject was seated in an acuustically shiclded chamber wearing stereo headphones. On the "focused attention" runs, he was given the same task instructions as in the lirst experiment, while on the "divided attention" runs he was told to "rementber as much as he could from both messages." Fach subject was then tested in three conditions: $(A)$ focus attention on left-ear message (F speaker). (B) focus attention on rightl-ear message ( $M$ speaker), and (C) divide altention between both messages.

Table 4

Mean EP Amplitudes ( \pm SE) at the Lateral Recording Sites (Expressed as Percentage of Amplitude at $C_{z}$ )

\begin{tabular}{llll}
\hline & F Probe (L Ear) & & M Probe (R Ear) \\
Left & Right & Left \\
\hline
\end{tabular}

(A) $P_{1}-N_{1}$

Passive (probes only)

Passive (probes and reversed speech)

Attend $M$ speaker

Attend $\mathrm{F}$ speaker

Passive (probes only)

Passive (probes and reversed speech)

Attend $M$ speaker

Attend $F$ speaker
$70.5 \pm 6.6$

$75.5 \pm 10.6$

$71.4 \pm 8.5$

$90.6 \pm 14.3$

$70.9 \pm 6.4$

$72.6 \pm 9.9$

$79.1 \pm 12.4$

$80.4 \pm 11.6$
$77.7 \pm 8.4$

$76.5 \pm 2.8$

$69.8 \pm 6.6$

$91.2 \pm 11.6$

(B) $\mathrm{N}_{1}-\mathrm{P}_{2}$

$66.3 \pm 8.4$

$65.3 \pm 9.0$

$74.5 \pm 9.1$

$68.9 \pm 6.2$

$70.9 \pm 4.5$

$87.5 \pm 5.6$

$81.2 \pm 7.0$

$79.8 \pm 6.0$
$61.1 \pm 8.2$

$65.1 \pm 5.8$

$61.5 \pm 5.6$

$78.7 \pm 9.4$

$59.0 \pm 4.6$

$68.7 \pm 7.8$

$54.8 \pm 4.4$

$62.7 \pm 7.9$ 
The experiment consisted of six runs, with the experimental conditions ordered in an ABCCBA design. The six possible orders of conditions were counterbalanced across subjects. The order of test administration was also counterbalanced within each pair of subjects.

\section{Results}

When attention was focused on the message in one ear, there was a highly significant disparity in percent correct answers between attended and unattended-ear tests $(p<.001)$, as in Experiment I (Table 6). When attention was divided between the two dichotic messages, the mean level of performance $(38.5 \%)$ was reduced significantly below that level achieved for the attended-ear messages in the focused condition $(57.5 \%)(p<.01)$. This average score during divided attention was significantly greater, however, than that obtained for the unattended-ear messages in the focused condition $(29.4 \%)(p<.025)$. Thus, an intermediate level of message recall was achieved during divided attention, but this level was somewhat lower than the overall average of attended and unattended message scores in the focused condition $(43.5 \%)[F(1.11)=4.74, p<.10]$. This overall between-conditions comparison did reach significance using a Wilcoxon sign-ranks test $(\mathrm{T}=13, \mathrm{~N}=12$, $p<.05$, two-tail). Thus it appears that subjects did not have the ability to increase the total amount of information recalled by deliberately attempting to listen to both messages at once.

\section{GENERAL DISCUSSION}

Selective listening to meaningful passages of speech undoubtedly involves processing mechanisms of a higher order than simply attending to a train of tone bursts and detecting occasional pitch changes, as in previous EP studies of attention. Proposed theories of speech perception have relied heavily on synthetic and constructive mechanisms, such as "analysis by synthesis" (Neisser, 1967), "linguistic extrapolation" (Hochberg, 1970), and the internal production of "speech plans" (Miller, Galanter, \& Pribram, 1960), while simple pitch discrimination or identification surely employs lower order systems. Despite such differences, the amplitude of the $N_{1}$ component of the auditory EP to probe stimuli embedded in the speech reflected the direction of selective attention in the same fashion as when subjects attended to dichotic trains of tone bursts (Hillyard et al., 1973; Schwent et al., in press a). The probe-evoked $P_{1}-N_{1}$ components were larger when a channel was being attended, even though the probes were not designated as relevant to the speech comprehension task and did not interfere with the subjects' ability to recall the monitored message. ${ }^{2}$

In at least one respect, however, selective listening to dichotic speech messages and to dichotic tone burst sequences are identical. Both tasks require a selection
Table 5

Mean Test Scores ( \pm SE) for Primary (Monitored) and Secondary (Nonmonitored) Messages (Percentage Correct Responses)

\begin{tabular}{lccc}
\hline & $\begin{array}{c}\text { Primary } \\
\text { Material } \\
\text { (P Test) }\end{array}$ & $\begin{array}{c}\text { Secondary } \\
\text { Material } \\
\text { (S Test) }\end{array}$ & Difference \\
\hline P test given first & $62.4 \pm 4.1$ & $25.4 \pm 2.5$ & $37.1 \pm 6.3$ \\
P test given second & $64.7 \pm 3.3$ & $27.0 \pm 2.2$ & $36.7 \pm 5.0$ \\
No probe & $64.0 \pm 4.0$ & $23.0 \pm 2.3$ & $41.0 \pm 4.9$ \\
\hline
\end{tabular}

Table 6

Mean Test Scores ( \pm SE) for Each Message Under Conditions of Focused and Divided Attention (Percentage Correct Responses)

\begin{tabular}{lccc}
\hline & \multicolumn{3}{c}{ Message Attended } \\
& Left & Both & Right \\
\hline Test left-ear message & $57.5 \pm 4.1$ & $33.8 \pm 3.4$ & $34.6 \pm 3.2$ \\
Test rightear message & $24.2 \pm 3.2$ & $43.0 \pm 3.5$ & $57.5 \pm 4.7$ \\
\hline
\end{tabular}

between channels separated by physical attributes of pitch and spatial position. It is a reasonable presumption, therefore, that the selective $N_{1}$ enhancement common to the two tasks is a correlate of the common "stimulus set" or "input selection" process. It is our hypothesis, then, that the $N_{1}$ amplitude is an index of an initial stage of selective attention that accords preferential processing to all stimuli belonging to a relevant channel (i.e., having the same pitch/space attributes), irrespective of the nature, complexity, or specific relevance of the material.

The tests for comprehension/recall of material on the two channels demonstrated that the instruction to give one channel primary emphasis did, in fact, produce processing of the dichotic messages. Not only were recall scores for attended-ear material much superior to those for the irrelevant message, but Experiment II showed that dividing attention between the two ears resulted in a lower level of performance than when an ear received focused attention. It is not clear, however, whether this selectivity occurs at an early. perceptual level or at some subsequent stage. such as in a limited memory store. The differential recall scores in the two ears and the similar differentiation of evoked activity at $80-130 \mathrm{msec}$ poststimulus suggests that this fairly early physiological selectivity could account for at least some of this behavioral selectivity. Although not tested behaviorally, it is reasonable to presume that the probe stimuli were also perceived differently in monitored and nonmonitored channels. Previous experiments which revealed little or no difference between probe detections in attended vs. nonattended dichotic speech messages (e.g., Lawson, 1966; Zelniker. Ratok, \& Medem, 1974) used pure tones as probes rather than vowel sounds matched to the speaker's voice. The present experiment is more comparable to that of Treisman and Geffen (1967). where the probes were actual words within the 
message and where a very high degree of selectivity between channels was obtained.

There is a noteworthy contrast between these results and those of a provocative study by Smith. Donchin. Cohen, and Starr (1970). These earlier authors used clicks to probe each ear while the subject was listening for target words in one ear. They found no significant effect on the EP due to the direction of attention. There are three points which might account for the difference in results between their study and the present experiment. First, as Smith and his colleagues suggested, clicks are simpler stimuli than linguistic probes. Perhaps clicks in both ears could be processed comparably if this processing does not interfere with that of the relevant stimuli. Another interpretation is that the clicks are more easily distinguished from speech than linguistic probes; the clicks may have a greater capacity to elicit an orientation reaction in a speech-sound environment. Second, the clicks were present at a rate approximately five times slower than our probes. Again, an orientation reaction may have been more recalcitrant at this slower rate. Third, the speech stimuli in the Smith et al. study were strings of letters and numbers presented at $1 \mathrm{pair} / \mathrm{sec}$. The meaningful prose spoken at a high rate may have required greater selectivity.

There is an apparent difference in the magnitude of the attention effects for each type of probe. The difference in the mean response between the active conditions is larger for the $F$ probe than for the $M$ probe. This effect could be explained by a relative difference in the accuracy with which the pitch of each probe was tuned to the speech. Explanations which rely on a comparison of attention effects cannot be supported by these data, since the overall mean responses to each type of probe are different. Therefore, one would have to make assumptions about the structure of the microvolt scale, in order to determine the relative magnitudes of the attention effects on responses to the two kinds of probes. Such assumptions are difficult to justify.

Although this experiment was not specifically designed to explore lateral asymmetries of EP components in relation to hemisphere specialization of function, some interesting left-right differences were observed. There was a strong overall tendency for probe-evoked $P_{1}-N_{1}$ and $N_{1}-P_{2}$ components to be larger at the left scalp site (just lateral to $C_{3}$ ) than at the mirror-image site; moreover, this left-sided preponderance was greater for probes presented to the contralateral (right) ear. Some of this lateral asymmetry may have resulted from the use of a unilateral reference electrode (right electrode), but Lehtonen and Koivikko (1971) reported that the earlobe is a rather inactive site for these late waves evoked by acoustic stimuli. The choice of reference could not have been solely responsible, however, for the increased left preponderance shown by the $N_{1}-P_{2}$ to right-ear probes when they were embedded in speech as opposed to when they were presented alore $(p<.01)$. The obvious conclusion that this shift of asymmetry is related to language processing must be tempered by the fact that it did not occur for left-ear probes and by our failure to reverse the headphones in half the runs to control for fortuitous acoustic differences in the two messages.

\section{REFERENCE NOTE}

1. Schwent, V. L., Snyder, E., \& Hillyard, S. A. Auditory c'voked potentials during multi-channel selective listening: Role of piach and localization cues. In preparation, 1976.

\section{REFERENCES}

Broadgent, D. E. Perception and communication. Londun: Pergammon, 1958.

Brondent, D. E. Decision and stress. New York: Academic, 1971.

Broadbent, D. E., \& Gregory, M. Stimulus set and respunse set: The alternation of attention. Quarterly Journal of Experimental Psycholugy, 1964, 16, 309.314.

Cherry, E. C. Some experiments on the recognition of speech with one and with two ears. Joumal of the Acousticul Society of America, 1953, 25, 975-979.

Hillyaro, S. A., Hink, R. F., Schwent, V. L., \& Picton, T. W. Electrical signs of selective attention in the human brain. Science, 1973, 182, 177-180.

HoCHBERG, J. Attention, organization, and consciousness. In D. I. Mostofsky (Ed.), Attention: Contemporary theory and analysis. New York: Appleton-Century-Crofts, 1970. Pp. 99-124.

LAwson, E. A. Decisions concerning the rejected channel. Quarterly Journal of Experimentul Psychology, 1906, 18. 260.265 .

Lehtonen, J. B., \& Kolvikko, M. J. The use of a noncephalic reference in recording cerebral evoked potentials in man. Electroencephalogruphy and Clinical Neurophysiology, $1971,31,154-156$.

Miller, G. A., Galanter, E., \& Pribram, K. Pluns and the structure of behavior. New York: McGraw-Hill, 1960.

MorAy, N. Attention: Selective processes in vision and hearing. New York: Academic, 1970.

Moray, N., \& O'Brien, T. Signal detection theory applied to selective listening. Journal of the Acoustical Suciety of Americu, $1967,42,765-772$.

NAATANEN, R. Selective attention and evoked potentials in humans-a critical review. Biological Psychology. 1975, 2. 2.37-307.

Neisser, U. Cognitive psychology. New York: Appleton. 1967.

Picton, T. W.. Hillyard, S. A., Krausz, H. J., \& Galambos, R. Hu nan auditory evoked potentials. 1: Evaluation of components. Electroencephalography and Clinical Neurophysiology. 1974. 36. 179.190.

Reynolds, D. Effects of double stimulation: Temporary inhibition of responsc. Psychological Bulletin, 1964, 62, 333-347. SCHWENT, V. L., \& Hillyard, S. A. Evoked potential correlates of selective attention with multi-channel auditory inputs. Electroencephalography and Clinical Neurophysiology, 1975, 38. $131 \cdot 138$.

Schwent, V. L.. Hitlyard. S. A., \& Galambos, R. Selective attention and the auditory vertex potential. l: Effects of stimulus delivery rate. Electmencephalography and Clinical $N$ ('urophysiology, in press. (a) 
Sohwhing, V. L.. Hillyard. S. A.. \& Galambos, R. Selective attention and the auditoly vertex potential. II: Etfects of signal intensity and masking noise. Electroencephalography und Clinical Nourophysiology, in press. (b)

Smith. D. B. D., Donchin, E., Cohen, F, \& Starr, A. Auditury averaged evoked putentials in man during selective behavioral listening. Electroencephalogrophy and Clinical Neturophysology, 1970, 28, 146-152.

Treisman, $\Lambda$. M. Selective attention in man. British Medical Bullorilu, 1964, 20. 12-16.

Treisman, A. M. Strategies and models of selective attention. Psicholugicul Review, 1969, 76, 282-299.

Treisman, A. M.. $\$$ Geffen, G. Selective attention: Perception or response? Quarterly Joumal of Experimental Psychology, $1907,19,1-17$.

UNDERWOOD, G., \& Moray, N. Shadowing and monitoring for selective attention. Quarterly Journal of Experimental Psychology, 1971, 23, 284.295.

Wilkinson, R. Г., \& Ashвy, S. M. Selective attention, cuntingent negative variation and the evoked potential. Bioloxicul Psychology, 1974, 1, 167-179.
Zelniker, T., Rattok, J.. \& Medem. A. Selective listening and threshold for tones appearing on a relevant and on all irrelevant input channel. Perception \& Psychophysics, 1974. 16. 5()$-52$

\section{NOTES}

1. The fact that $S$-test scores were signiticantly higher than chathe raises the possibility that some questions had self-evident answers or that the subjects were relying on previous knowledge of the stories. Oecasional shitts of attention or intrusions from the nonmunitored channel cannot be ruled out, however.

2. A further test of the role played by the probes would be to compare the responses to the phonemes in context with those out of context. Unfortunately, we did not have the technical facilities to conduct this experinent.

(Received for publication October 31, 1975; revision received January $19,1976$. 